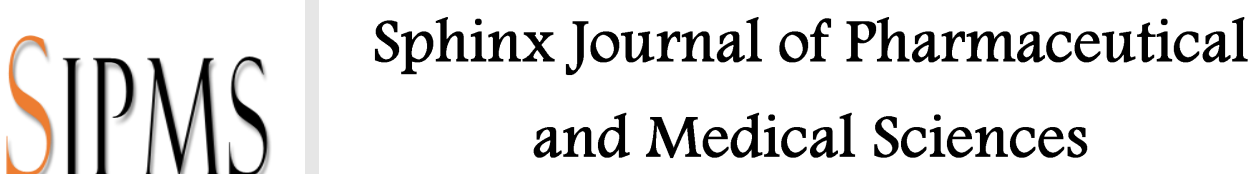

\section{QUALITY CONTROL OF HERBAL PRODUCTS IN THE EGYPTIAN MARKET USED FOR WEIGHT MANAGEMENT}

\author{
Lourin G. Malak ${ }^{1}$, Omnia A. El-Helaly ${ }^{2}$ and Amany S. Ahmed ${ }^{1,3^{*}}$ \\ ${ }^{1}$ Department of Pharmacognosy, Faculty of Pharmacy, Assuit University, 71526, Assuit, Egypt \\ ${ }^{2}$ Centre for Pharmaceutical Studies and Research of Medicinal Plants, Faculty of Pharmacy, \\ Assuit University, 71526, Assuit, Egypt \\ ${ }^{3}$ Department of Pharmacognosy, Faculty of Pharmacy, Sphinx University, New Assiut 10, \\ Egypt
}

\begin{abstract}
Regime herbal teas in the form of fine powder (tea bags) are commonly used as phytotherapy in Egypt. This practice is based on family tradition reinforced by current trends reverting to the ingestion of natural products. The work aimed to evaluate the quality control of the two commercial herbal tea products present in the Egyptian market used for treatment of obesity; commercial herbal medicine (S1 and S2), through microscopical identification of their diagnostic elements. In addition, detection of the main active secondary metabolites were performed using the phytochemical screening tests for anthraquinones, flavonoids, saponins, phenolics, carbohydrates, and volatile oil. The used Egyptian commercial herbal medicines for weight loss have proven to match the identity and purity of the genuine monoherbs and can be subjected for further clinical trials to evaluate their safety and efficacy.
\end{abstract}

Keywords: Quality control, obesity, herbal medicine, microscopical characters, phytochemical analysis.

\section{INTRODUCTION}

Obesity is a metabolic syndrome associated with multiple medical complications characterized by increasing body weight and accumulation of fat in the body. The number of obese patients is increasing globally ${ }^{1}$. The pharmaceutical anti-obesity drugs have shown many adverse reactions through affecting monoamine neurotransmitters causing psychiatric, cardiac-related adverse effects and drug abuse ${ }^{1 \& 2}$. Therefore, people seek out alternative therapies that are effective, economic and safe ${ }^{3}$.

Herbal medicines play an important role in modern human life as they have been used in the alleviation of human diseases especially by the developing world's population. This is known as complementary or alternative systems of medicine which can be related to the phytoconstituents of herbal drugs which are welcomed by several patients due to their efficacy, safety, low side effects and low cost ${ }^{4}$. Recent studies have revealed that traditional herbal medicines are safe at high dose and effective in increasing metabolism and reducing body weight ${ }^{3}$. Herbal medicines are available in many forms such as teas, creams, tinctures, and poultices.

National process of regulation and registration of herbal medicines varies from country to country. The World Health Organisation (WHO) has published criteria and guidelines to ensure the safety, efficacy, and quality of herbal medicines. Lack of regulation 
and quality control may cause several adverse events such as adulteration threat ${ }^{5}$.

The microscopic studies of plants can play a significant role for authentication of genuine herbs and quality control of herbal medicine. Moreover, the identification of the secondary metabolites is considered as a useful tool for quality control ${ }^{6}$.

The aim of the present study was to control the quality of the most two common weight loss herbal preparations in Egypt microscopically and phytochemically. Samples of two forms of commercial tea bags were microscopically studied. Observed diagnostic elements were compared with those of genuine monoherbs in the reference bibliography ${ }^{7}$. In addition, qualitative tests were done for detection of the presence of anthraquinones, flavonoids, saponins, phenolics, carbohydrates, and volatile oil as they are considered the main active constituents of the herbal species found in the studied herbal mixtures ${ }^{8}$.

\section{MATERIAL AND METHODS}

\section{Microscopical examination}

Two commercial herbal medicines used for weight loss were selected (samples S1, S2). Both of them are in the form of tea bags. The powdered herbal mixtures were boiled with $5 \%$ sodium hydroxide at water bath for 5-10 min. followed by several washes with distilled water in order to disintegrate the tissues. The obtained preparations were examined and described by using Olympus optical microscope (Tokyo, Japan). The diagnostic elements for each herbal drug in the mixture were identified via microscopical observation and compared with those described for each species in the bibliography ${ }^{7}$.

\section{Preliminary phytochemical screening Extraction of powdered samples}

The extractions and all the qualitative methods have been done according to the most common and reliable methods ${ }^{8 \& 9}$. Powdered samples of tested tea bags were homogenized in $70 \%$ methanol and then refluxed for $30 \mathrm{~min}$. After cooling, the liquid was filtered and the extracts were subjected to phytochemical screening tests.

\section{Phytochemical screening tests}

Phytochemical screening of the extracts was carried out according to the standard procedures $^{9 \& 10}$.

Flavonoids: filter paper was dipped in alcoholic solution of the powder, then exposed to ammonia vapor. A yellow spot was observed on the filter paper due to the presence of flavonoids.

Phenolic: To the crude extract add $0.5 \% \mathrm{FeCl}_{3}$ solution. Formation of bluish black precipitate indicates the presence of phenolic compounds.

Saponin: $5 \mathrm{mg}$ of powdered mixture was mixed with $20 \mathrm{ml}$ of distilled water and then agitated in a graduated cylinder for 15 minutes. Formation of foam indicates the presence of saponins.

Salkowiski test: Approximately $2 \mathrm{mg}$ of dry extract was shaken with $1 \mathrm{ml}$ of chloroform and a few drops of concentrated sulfuric acid were added along the side of the test tube. A red brown color formed at the interface indicates the presence of triterpenoidal saponins.

Carbohydrate: Fehlings A and Fehlings B reagents were mixed and few drops of extract were added. Reddish brown coloured precipitate is obtained after boiling in water bath.

Anthraquinone: $3 \mathrm{ml}$ of extract was added to $3 \mathrm{ml}$ of Benzene and then $5 \mathrm{ml} \mathrm{NH}_{3}(10 \%)$ as added. Red coloration in ammonical layer is observed.

Volatile oils: $0.5 \mathrm{ml}$ of extract was mixed with $5 \mathrm{ml}$ of sudan III. Red colour is observed.

\section{RESULTS AND DISCUSSION}

Determination of the quality, safety and efficacy of commercial herbal medicines has become an important issue and it became necessary to check on their quality, efficacy, and safety. The quality control of the two weight loss products most commonly used in Egypt was performed. It showed that there are eight herbal species used in their preparation as various species were common components 
(Table 1). The herbal species in the tea bags were nettle, liquorice, marjoram, celery, senna, calendula, chicory, and fennel. These herbal species were reported to be effective in the treatment of obesity. Nettle was found to lower blood glucose level and enhance insulin secretion in addition to decreasing the free fatty acid - induced inhibition of insulin ${ }^{11}$. Kamisoyama et al. found that liquorice decreased plasma cholesterol concentration as well as abdominal adipose tissue weight ${ }^{12}$. Marjoram is effective in reducing weight as it showed hypolipidaemic and hypocholesterolemic effects ${ }^{13}$. Similar results were reported for chicory to lower plasma triglyceride and cholesterol levels ${ }^{14}$. The study published by Ahmed et al. showed that the herbal mixture of chicory and marjoram has synergistic effect in treating obesity. It reduces food intake and improve liver function and thyroid activity ${ }^{15}$. A recent studies showed that senna has antidiabetic effect, in addition to the laxative effect of sennosides and hence senna can control obesity ${ }^{16 \& 17}$. Fennel decreases food intake and increases satiety by stimulating cholecystokinin release $^{18}$. Celery and calendula were found to contain compounds that are effective in reducing obesity ${ }^{19 \& 20}$.

Table 1: Microscopical botanical analysis and label appraisal.

\begin{tabular}{||l|l|l|}
\hline Product & $\begin{array}{l}\text { Species declared } \\
\text { on the label }\end{array}$ & $\begin{array}{c}\text { Species found at } \\
\text { micrographic analysis }\end{array}$ \\
\hline S1 & nettle & Urtica dioica \\
\hline & liquorice & Glycyrrhiza glabra \\
\hline & marjoram & Origanum majorana \\
\hline & celery & Apium graveolens \\
\hline & senna & Cassia acutifolia \\
\hline & calendula & Calendula officinalis \\
\hline & chicory & Chicorium intybus \\
\hline S2 & chicory & Not found \\
\hline & senna & Cassia acutifolia \\
\hline & fennel & Foeniculum vulgare \\
\hline
\end{tabular}

The composition of herbal mixture S1 as declared on the label fully coincided with the observations of the microscope analysis, confirming its authenticity. On the contrary, some degree of adulteration was observed in herbal mixture $\mathrm{S} 2$ as it showed one elimination; chicory. No additional elements, belonging to herbal species other than the ones listed in the labels, appear in the microscopical examination. The diagnostic elements of the components observed in the microscopical examination are shown in figure 1.

Sample S1 contained seven species; Urtica dioica, revealed by the observation of stinging hairs which are initiated as conical bumps from the epidermal cells (Fig. 1a); Glycyrrhiza glabra, identified through the observation of crystal sheath and cork cells (Fig. 1b, c); Origanum majorana, identified by the presence of labiaceous hairs (Fig. 1d); Apium graveolens, characterized by the presence of fragments of vittae (Fig. 1e); Cassia acutifolia, identified by the observation of crystal sheath, paracytic stomata and conical unicellular non glandular hairs (Fig. 1b, f); Calendula officinalis, revealed through the presence of spiny pollen grains (Fig. 1g); and Chicorium intybus, characterized by the presence of non glandular hairs (Fig. 1h, i). The label of sample S2 contained three species; Foeniculum vulgare, revealed by the observation of fragments of vittae (Fig. 1j), Cassia acutifolia, identified through the observation of crystal sheath and conical unicellular non glandular hairs (Fig. 1k, 1) and it showed one elimination; Chicorium intybus.

In addition, qualitative determination of relevant substances of the plants was performed by phytochemical analysis. Tests for anthraquinones, flavonoids, saponins, phenolics, carbohydrates, and volatile oil were performed.

Observation of Phytochemical Screening. The qualitative phytochemical analysis was performed using standard procedures ${ }^{10}$. The phytochemical analysis of powdered samples gave the positive results for anthraquinones, flavonoids, saponins, phenolics, carbohydrates, and volatile oil. 


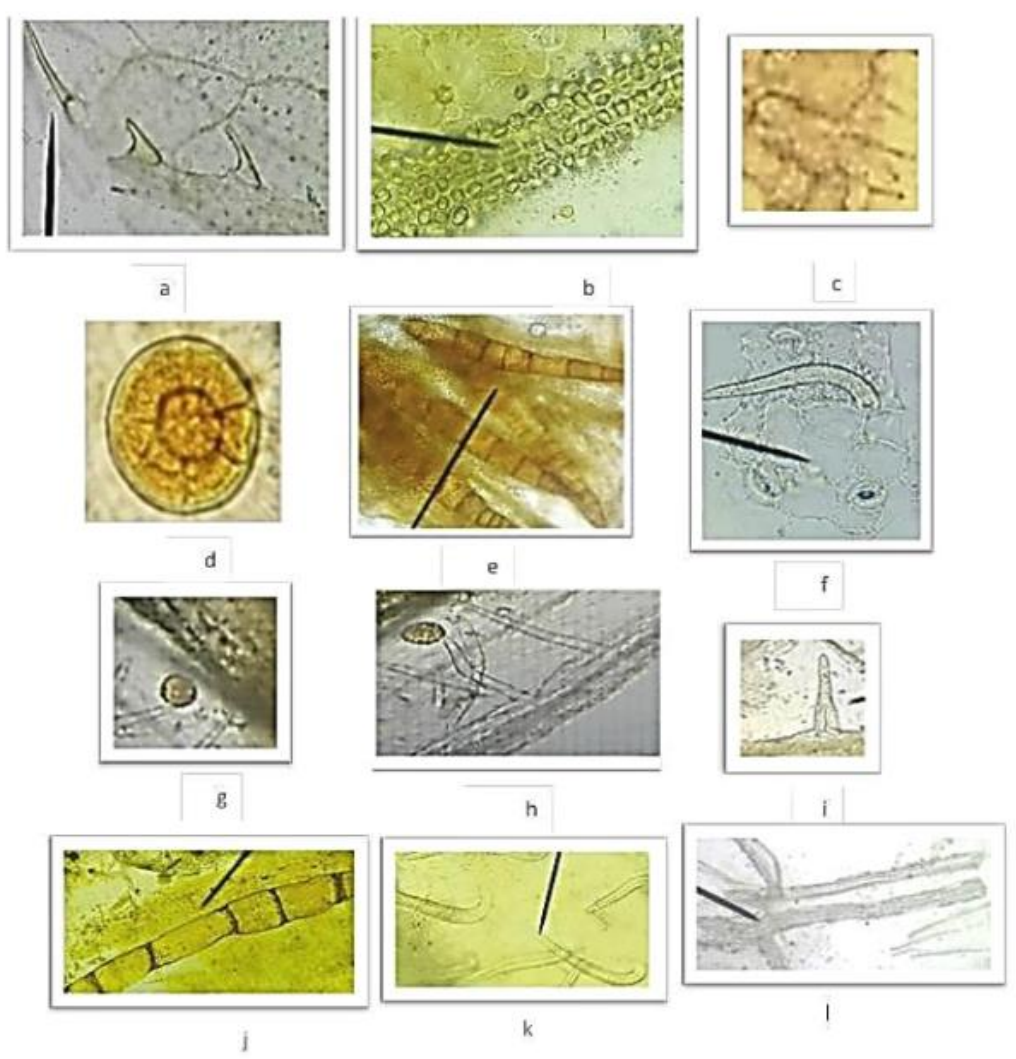

Fig. 1: The diagnostic elements of the components observed in the microscopical examination of the powdered mixtures under investigation (S1 and S2).

*magnification power of a,d,g,h x 20, b,c,e,f,i,j,k,l x10.

In the studied products, a total of eight different species were found. Adulteration was not found in herbal mixture S1 while the label is missing the proportions of the herbs used. Based on the current Egyptian guidelines for registeration of herbal medicines, the equivalent quantity or the ratio of plant material to plant preparation must be stated ${ }^{21}$. On the other hand, one elimination was found in herbal mixture S2 while showing complete and correct information on the label. Labels of both samples don't mention additional information concerning the side effects and contraindications of each herbal species found in the mixture.

\section{Conclusion}

The two examined herbal tea bags showed good quality except for the absence of one element in one of the samples (S2). In addition, the label of (S1) is missing the proportions of the herbs used. In general, the studied herbal mixtures had an acceptable botanical quality. These results revealed the importance of quality control as a tool to protect the rights of herbal medicine consumers.

\section{Conflict of interests}

Authors do not have any conflict of interests.

\section{REFERENCES}

1- Y. Liu, M. Sun, H. Yao, Y. Liu, R. Gao, "Herbal medicine for the treatment of obesity: An overview of scientific evidence from 2007 to 2017", Evid. Based Complement. Alternat. Med., 2017, 2017, 17 pages.

2- P. R. Pandeya, "Evaluation of anti-obesity activity of an herbal formulation (F2) in DIO mice model and validation of UPLCDAD method for quality control", Appl. Sci., 2021, 11, 7404. 
3- E. Valizadeh, F. Ghalichi, A. Ostadrahimi, "Traditional herbal medicine for weight management: A review", Int. J. Med. Res. Health Sci., 2016, 5 (11), 393-399.

4- J. B. Calixto, "Efficacy, safety, quality control, marketing and regulatory guidelines for herbal medicines (phytotherapeutic agents)", Braz. J. Med. Biol. Res., 2000, 33, 179-189.

5- World Health Organization, "WHO Guidelines for Assessing Quality of Herbal Medicines with Reference to Contaminants and Residues", World Health Organization, 2007, https://apps. who.int/iris/handle/10665/43510.

6- A. Balekundri, V. Mannur, "Quality control of the traditional herbs and herbal products: A review", Future J. Pharm. Sci., 2020, 6, 67.

7- N. B. Jackson, D. W. Snowdon, "Atlas of Microscopy of Medicinal Plants Culinary Herbs and Spices", London, Belhaven Press, 1990, 257.

8- J. B. Harborne, "Phytochemical Methods, A guide to Modern Techniques of Plant Analysis", Chapman and Hall: New York, 1998, 1-150.

9- G. E. Trease, W. C. Evans, "A Textbook of Pharmacognosy", Academic press: London, 1989, 22-40.

10- C. K. Kokate, A. P. Purohit, S. B. Gokhale, "Pharmacognosy", Nirali Prakashan, New Delhi, India, 2006, 593595.

11- D. N. Obanda, P. Zhao, A. J. Richard, D. Ribnicky, W. T. Cefalu, J. M. Stephens, "Stinging Nettle (Urtica dioica L.) attenuates FFA induced ceramide accumulation in 3T3-L1 adipocytes in an adiponectin dependent manner", PLoS ONE, 2016, 11 (3), 1-13.

12- H. Kamisoyama, K. Honda, Y. Tominaja, S. Yokota, S. Hasegawa, "Investigation of the anti-obesity action of licorice flavonoid oil in diet-induced obese rats", Biosci. Biotechnol. Biochem., 2008, 72 (12), 3225-3231.

13- D. R. Negm, A. A. Sonbul, E. A. Bantan, H. S. Bukhari, S. M. Basalamah, A. M. Basfar, et al., "Assess the efficiency of marjoram on weight control and body composition of male and female adult students", Int. J. Adv. Res., 2017, 5 (3), 1898-1906.

14- K. Janda, I. Gutowska, M. Moritz, K. Jakubczyk, "The common cichory (Cichorium intybus L.) as a source of extracts with health-promoting properties - A review", Molecules, 2021, 26, 18141828.

15- L. A. Ahmed, R. S. Ramadan, R. A. Mohamed, "Biochemical and histopathological studies on the water extracts of marjoram and chicory herbs and their mixture in obese rats", Pak. J. Nutr., 2009, 8 (10), 1581-1587.

16- M. Martorell, N. Castro, M. Victoriano, X. Capo, S. Tejada, S. Vitalini, et al., "An update of anthraquinone derivatives emodin, diacerein, and catenarin in diabetes", $\quad$ Evid. Based Complement. Alternat. Med., 2021, 1-13.

17- R. O. A. Kerim, A. G. A. Elisa, B. V. J. Lucia, R. R. C. Martin, G. C. T. Arcelia, R. L. E. Javier, "Impact of Cassia acutifolia infusion on glucose levels in obesity and diabetes rat model", $\boldsymbol{J}$. Pharmacopuncture, 2017, 20 (3), 201206.

18- N. A. Elghazaly, E. H. Radwan, H. H. Zaatout, M. M. Elghazaly, N. E. Allam, Beneficial effects of fennel (Foeniculum Vulgare) in treating obesity in rats", $\boldsymbol{J}$. Obes. Manag., 2019, 1 (2), 16-33.

19- N. K. Beltagy, A. H. Mahmoud, A. Ghazi, S. M. Metwalli, "Using of celery (Apium graveolens L) for lowering obesity of experimental rats", J. Food and Dairy Sci., Mansoura Univ., 2018, 9 (2), 59-67.

20- A. Zaki, A. Ashour, A. Mira, A. Kishikawa, T. Nakagawa, Q. Zhu, et al., Biological activities of oleanolic acid derivatives from Calendula officinalis seeds", Phytother. Res., 2016, 30, 835841.

21- Egyptian Guidelines For Registration of Herbal Medicines, "Egyptian Drug Authority (EDA) Central Administration for Pharmaceutical Products", 2021. 


\section{SJPMS}

\section{Sphinx Journal of Pharmaceutical and Medical Sciences

ضبط جودة المنتجات العشبية في السوق المصري المستخدمة في ضبط الوزن

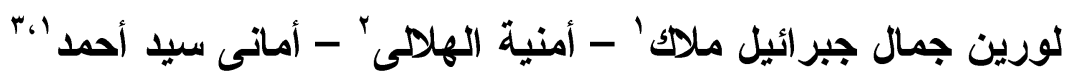

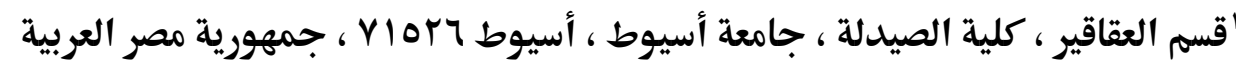

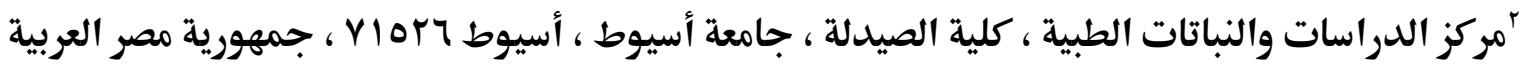
"قسم العقاقير ، كلية الصيدلة ، جامعة سفنكس ، أسيوط الجديدة • 1 ، جمهورية مصر العربية

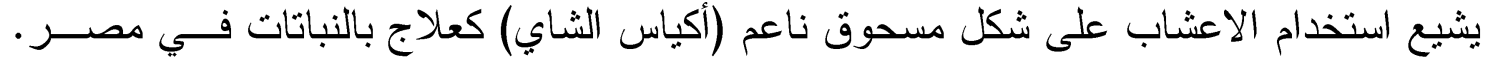
تستند هذه الممارسة إلى التقاليد العائلية التي تعززها الاتجاهات الحالية التي تشجع على تناول المنتجات

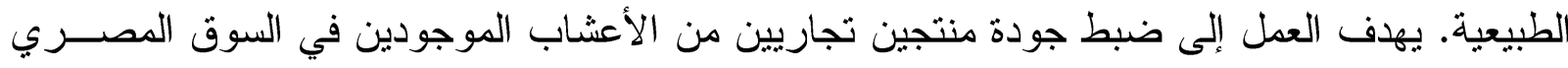

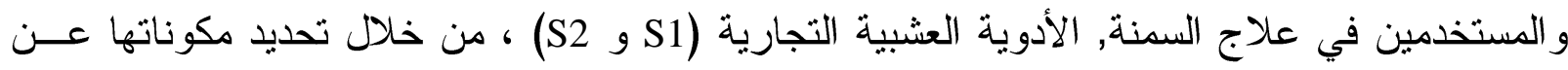
طريق استخدام المجهر • بالإضافة إلى ذلك ، تم إجراء الكشف عن مكوناتها الكيميائية النشطة الرئيسية

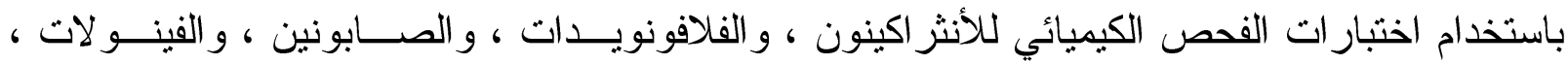
و الكربوهيدر ات ، و الزيوت المتطايرة. وقد أثثتت الأدوية العشبية التجارية المصرية المستخدمة لفقــــان

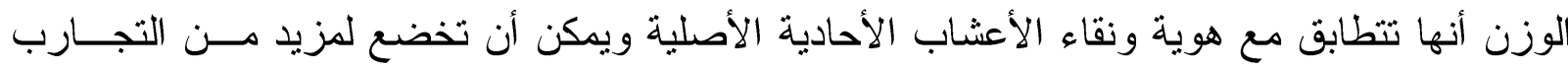
السريرية لتقييم سلامتها وفعاليتها. 